Corresponding Author: Santiago Zazo Del dedo sanzadel@doctor.upv.es

Received: 26 November 2019 Accepted: 13 May 2020

Published: 2 June 2020

Publishing services provided by Knowledge E

(c) Santiago Zazo Del dedo et al. This article is distributed under the terms of the Creative Commons Attribution License, which permits unrestricted use and redistribution provided that the original author and source are credited.

Selection and Peer-review under the responsibility of the ICEUBI2019 Conference Committee.

\section{Qualitative Approach for Assessing Runoff Temporal Dependence Through Geometrical Symmetry}

\author{
Santiago Zazo Del dedo ${ }^{1}$, Hector Macian-Sorribes ${ }^{1}$, Cristina Maria Sena Fael ${ }^{2}$, \\ Ana-María Garía-Martín³, Jose-Luis Molina ${ }^{3}$, and Manuel Pulido-Velazquez ${ }^{1}$ \\ ${ }^{1}$ Universitat Politècnica de València \\ ${ }^{2}$ University of Beira Interior \\ ${ }^{3}$ Salamanca University
}

\section{Abstract}

Currently, noticeable changes in traditional hydrological patterns are being observed on the short and medium-term. These modifications are adding a growing variability on water resources behaviour, especially evident in its availability. Consequently, for a better understanding/knowledge of temporal alterations, it is crucial to develop new analytical strategies which are capable of capturing these modifications on its temporal behaviour. This challenge is here addressed via a purely stochastic methodology on annual runoff time series. This is performed through the propagation of temporal dependence strength over the time, by means of Causality, supported by Causal Reasoning (Bayes' theorem), via the relative percentage of runoff change that a time-step produces on the following ones. The result is a dependence mitigation graph, whose analysis of its symmetry provides an innovative qualitative approach to assess time-dependency from a dynamic and continuous perspective against the classical, static and punctual result that a correlogram offers. This was evaluated/applied to four Spanish unregulated river sub-basins; firstly on two Douro/Duero River Basin exemplary case studies (the largest river basin at Iberian Peninsula) with a clearly opposite temporal behaviour, and subsequently applied to two watersheds belonging to Jucar River Basin (Iberian Peninsula Mediterranean side), characterised by suffering regular drought conditions.

Keywords: Causal reasoning, Theorem of Bayes, Temporal dependence propagation, Runoff time series, Water resources management

\section{Introduction}

It is evident that traditional patterns of hydrological processes on a particular territory are suffering significant alterations [1], which is adding a growing variability into its cyclical behaviour [2]; in addition to become non-stationarity in a typical situation to deal with [3]. This is due mainly to the intensification of hydrological phenomena, as result of global warming [4], which is producing more frequent, unpredictable and severe hydrological 
extreme events, such as droughts or floods [5]. In this sense, South and South-East of Europe show a significant increase in the frequency of droughts [6]. All this is increasing uncertainty on water systems behaviour, especially palpable over runoffs series [3].

In this sense, time series dependence has been traditionally studied by means of correlograms. However, it is well known that this approach provides an average idea and a static analysis of temporal dependence [7]. In these circumstances, there is a strong need to increase the knowledge on temporal behaviour of the hydrological series [8], through new analytical strategies which are capable of capturing the induced/diffused modifications into the general behaviour of the time series, as a result of these new hydrological realities [9].

Currently, the high capacity of data processing is permitting the appearance of novel alternatives based on Artificial Intelligence (AI) [7]. These are opening new perspectives to discover the logical and non-trivial time-dependency structure that underlies into hydrological time series, able them to reduce the intrinsic uncertainty associated to hydrological phenomena [10].

This is here addressed stochastic/dynamically through Causality, supported by Causal Reasoning (CR). This a powerful analytical methodology to discover reasoning patterns focused on the cause [11]. According to new trends in hydrological stochastic research [12], this is done by a hybrid approach with an Autoregressive Moving Average (ARMA) model, and a Probabilistic Graphics Model (Al technique) where Bayes' Theorem is implemented.

This research provides a novel geometrical approach to assess time-dependency dynamically. This is a straightforward consequence of the active research line, initiated by [12], which is focused on improving the knowledge of temporal behaviour of water resources from Causality.

\section{Case Studies}

High variability is identity trait of Spanish water resources, due primarily to an irregular rainfall distribution, among wet north (around 2,000 mm/year), and dry south-east (less than $200 \mathrm{~mm} /$ year) [13]-[15], which is intensified by low capacity of retention of Spanish soils; on average a $9 \%$ versus $34 \%$ in the rest of Europe [16].

Case study selection criteria were based on the general pattern described above jointly with time series from unregulated rivers stretches (runoffs in natural conditions). Runoff data were obtained through the network of gauging stations (GS), belonging to Douro/Duero and Jucar Spanish River Authorities [17], [18]. Two case studies, Porma 
(north; GS "Camposolillo") and Adaja (south of the northern sub-plateau; GS "Adaja”), located in Douro/Duero River Basin (the largest basin in the Iberian Peninsula) [3] and with a clearly opposite temporal behaviour, and another two, Cabriel (GS "Pajaroncillo") and Mijares (GS "El Terde"), belonging to Jucar River Basin (the most extensive basin in the Eastern peninsular and characterized by important problems of drought) [2], [19] (Figure 1).

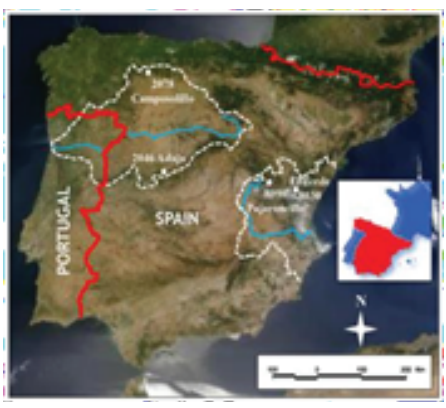

Figure 1: Location of case studies. The numbers indicates the code of gauging stations. (Source: [20])

All case studies have got an annual time series longer than 30 years (minimum time period indicated by the World Meteorological Organization [21], [22]). On the other hand, these case studies are not related to each other (historical series with different time periods). Moreover, in the Douro/Duero case studies there are not missing data in the annual runoff series. In contrast, the annual time series from Jucar case studies were built by monthly runoff records, and the minimum missing data (one in Cabriel, and four in Mijares) were completed based on average trend observed in the historical records. Figure 2 shows annual time series considered in this research.

\section{Methodology}

This research was articulated in three sequential phases. Firstly, an initial pre-analysis phase on historical series was done (Phase-1). This comprised: i) a traditional statistical analysis, ii) generation of equiprobable synthetic runoff series through a parsimonious and unconditioned ARMA $(1,1)$ model and iii) the obtainment of correlogram of historical time series, as classic temporal behaviour indicator. After that (Phase-2), synthetic series were applied to populate the Causal Reasoning, supported by Bayesian modelling (Bayes' theorem). This provided the logical time-dependency structure that inherently underlies into hydrological series. To conclude, in Phase-3, a post-analysis was performed that comprised the evolution of temporal dependence over time, through a dependence mitigation graph. 

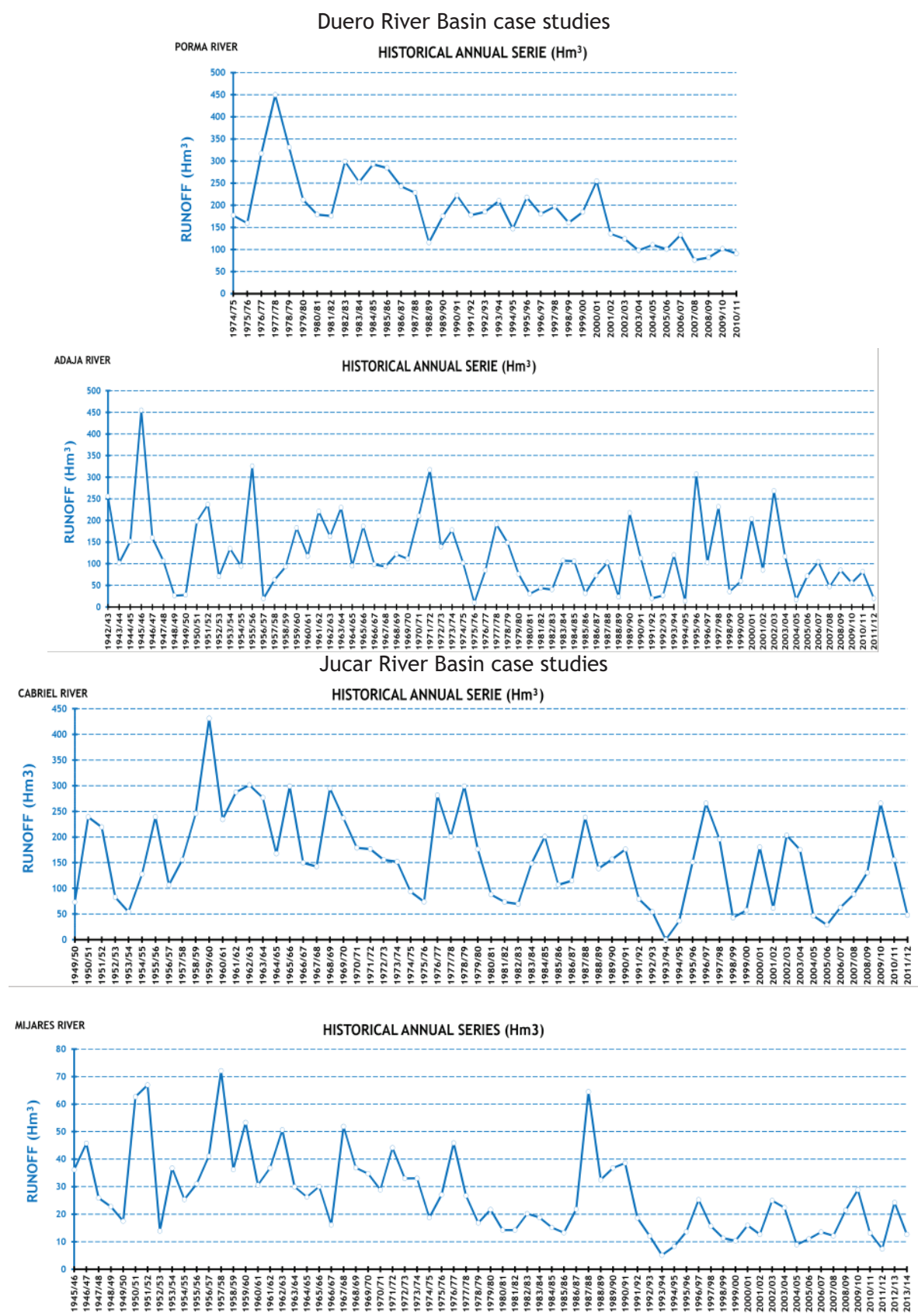

Figure 2: Runoff annual time series.

For an in-depth review of theoretical and mathematical frameworks, the reader is invited to refer to the following research papers [2], [7], [9]. Despite this, it seems appropriate to indicate a brief description of the theoretical basis applied in this research.

In this sense, and according to [9] " $C R$ is carried out over a set of random decision variables (water years in this case), which are consecutively interconnected, and a set of conditional probability tables between decision variables. The quantification of the variables' relationship strength is performed by Bayes' theorem, which is propagated over time by the conditional probability; in this way the probability distributions are 
calculated for each decision variable". In addition, the propagation of Bayes' Theorem enables a time-step by time-step and dynamic analysis of the time-dependency evolution over the time. This is done via the relative percentage of runoff change that a time-step dynamically produces on the following ones [2], supported by software HUGIN Expert version 7.3 [23].

This methodological framework provides a curve of propagation of dependence for each decision variable. Afterward, all of them are encompassed through a wraparound of dependence propagations, positive (W-MAX) and negative (W-MIN). Next, these curves (W-MAX and W-MIN) are fitting to mathematical functions. The achieved result is a graph, which has been denominated Dependence Mitigation Graph (DMG), whose analysis of its symmetry provides an innovative qualitative approach to assess time-dependency from a dynamic and continuous perspective.

\section{Experimental Results}

\subsection{Pre-analysis phase}

Table 1 summarizes the main parameters of statistical analysis carried out. Adaja case study is the most variable and less Gaussian of the cases, with a variation coefficient of $72.46 \%$ and skewness coefficient of 1.23 . On the other side, Porma case presents the lowest variation coefficient of all (42.30\%), and Cabriel the lowest skewness coefficient (0.50).

TABLE 1: Main statistical parameters of Historical series (annual runoff series).

\begin{tabular}{l|c|c|c|c|}
\hline Parameters & \multicolumn{2}{|c|}{ Douro/Duero case studies } & \multicolumn{2}{c|}{ Jucar case studies } \\
\hline & \multicolumn{1}{|c|}{ Porma } & Adaja & Cabriel & Mijares \\
\hline Water years: & $1974 / 75-2010 / 11$ & $1942 / 43-2011 / 12$ & $1949 / 50-2011 / 12$ & $1945 / 46-2013 / 14$ \\
\hline Time period (years): & 37 & 70 & 63 & 69 \\
\hline Mean $\left(\mathrm{Hm}^{3}\right)$ : & 191.29 & 122.12 & 158.52 & 27.06 \\
\hline $\begin{array}{l}\text { Standard deviation } \\
\left(\mathrm{Hm}^{3}\right) \text { : }\end{array}$ & 80.92 & 88.48 & 88.40 & 15.23 \\
\hline Variation Coef. (\%): & 42.30 & 72.46 & 55.77 & 56.29 \\
\hline Skewness Coef.: & 0.98 & 1.23 & 0.50 & 1.05 \\
\hline
\end{tabular}

In Table 2 it can clearly see that Synthetic series (S.S.) preserve the main features of the historical series, such as mean and standard deviation.

In contrast, Figure 3 shows the correlograms, as typical temporal behavior indicator. In this sense, the most independent behavior is shown in the Adaja case study, where all 
TABLE 2: Reliability of the generated Synthetic Series from ARMA (1,1) model. Comparison versus Historical series.

Parameters
Mean $\left(\mathrm{Hm}^{3}\right)$ :
Standard deviation
$\left(\mathrm{Hm}^{3}\right)$ :

\begin{tabular}{|c|c|}
\hline \multicolumn{2}{|c|}{ Douro/Duero case studies } \\
\hline Porma & Adaja \\
\hline H.S. vs S.S. & H.S. vs S.S. \\
\hline $191.29 / 192.59$ & $122.12 / 124.34$ \\
\hline $80.92 / 74.66$ & $88.48 / 84.94$ \\
\hline
\end{tabular}

\begin{tabular}{|c|c|}
\hline \multicolumn{2}{|c|}{ Jucar case studies } \\
\hline Cabriel & Mijares \\
\hline H.S. vs S.S. & H.S. vs S.S. \\
\hline $158.52 / 157.19$ & $27.06 / 26.75$ \\
\hline $88.40 / 93.82$ & $15.23 / 16.12$ \\
\hline
\end{tabular}

time-lags are inside of independent region defined by Anderson limits (95\% and 99\%). The highest correlation coefficients are displayed by Porma correlogram $\left(r k_{1}=0.67\right.$ and $r k_{5}$ and $6=0.52$ ). Furthermore, a detailed analysis of correlograms highlights correlation coefficients ( $r k$ ) very close to upper Anderson limits: Porma $r k_{2}(99 \%), r k_{4}$ and $r k_{9}$ (95\%); Adaja $r k_{6}$ (95\%); Cabriel $r k_{7}$ (95\%) and Mijares $r k_{2}$ to $r k_{4}$ (95\% and 99\%) and $r k_{7}$ to $\left.r k_{10}(95 \%)\right)$. It can be clearly appreciated that this kind of analysis offers indetermination points $\left(r k_{i}\right.$ very close to Anderson limits; see Porma $r k_{9}$, Mijares $r k_{2}$ and $\left.r k_{3}\right)$. In this sense, these results provide uncertainty in the correlograms analysis due to the average and static nature of the results that this method provides. Subsequently, through DMG these will be eliminated (please, see Figure 5).

\subsection{Causal Reasoning. Non-trivial time-dependency structure}

The suitability of the methodological framework, applied to modeling complex systems as natural ones (water resources), is evidenced through Graph of Marginal Dependencies in Figure 4 [9]. Each detected link represents an independence/dependence relationship. In this way, CR has been able to highlight non-trivial dependency relationships (time-lag >1) amongst decision variables (water years, in this case).

This set of relationships defines and provides the logical and non-trivial timedependency structure, which inherently underlies into hydrological series. This is an important advantage when it is intended to address a dynamic dependence analysis throughout all decision variables of the time series.

\subsection{Post-analysis phase. Qualitative geometrical approach for time-dependence assessing}

According to temporal behavior shown by exemplary case studies belonging to Douro/Duero basin (Figure 3) a symmetry analysis was carried out by means of DMGs 
Porma. GS “Camposolillo”. Code number 2078

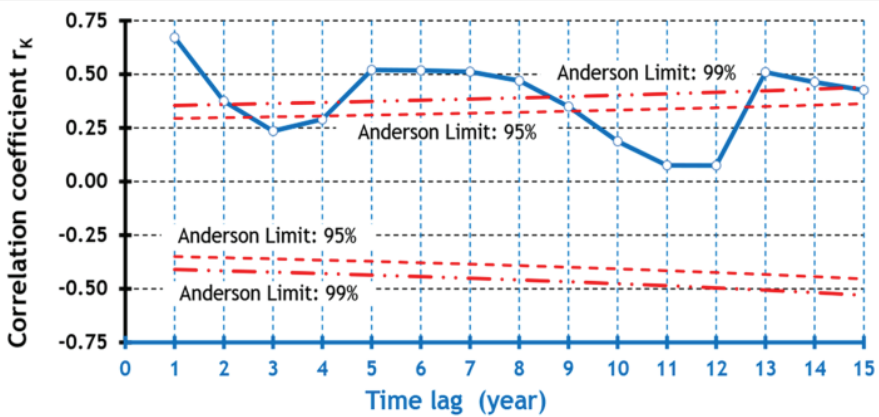

Adaja. GS “Ávila”. Code number 2046

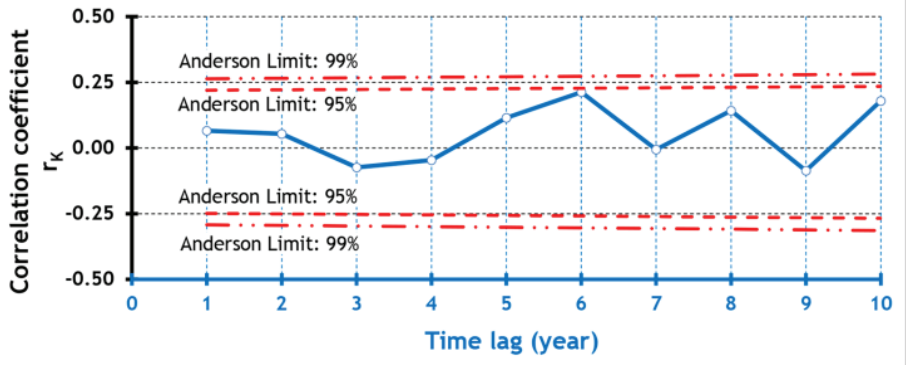

Cabriel. GS “Pajaroncillo”. Code number 8090

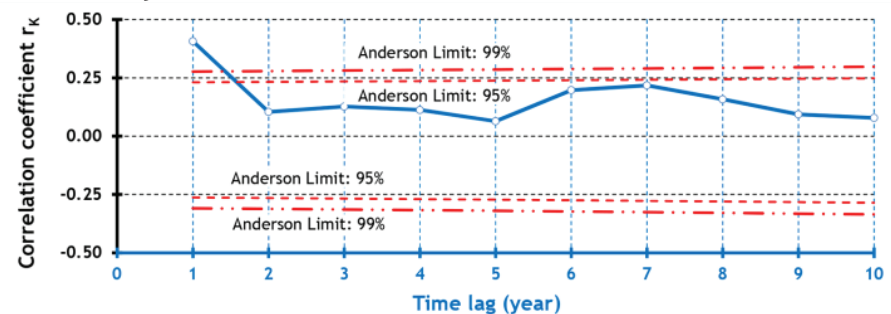

Mijares. GS “El Terde”. Code number 8030

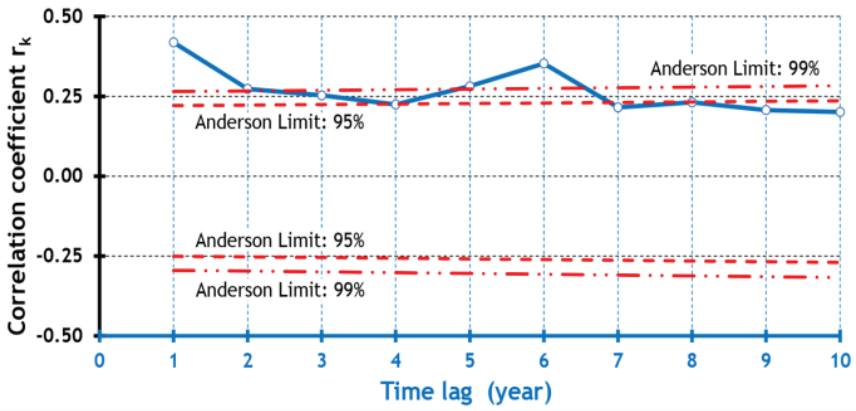

Figure 3: Correlograms and probability limits of an independent series ( $95 \%$ and $99 \%$ probability levels). Anderson limits define the temporal independent region.

(Figure 5). It should be noted these cases present an evident opposite temporal behavior; the first (Porma) dependent and second one (Adaja) independent. Then, this approach was validated by Jucar case study. In this sense, and based on correlograms (Figure 3), Cabriel case presents a strong dependent behavior in time-lag 1, and for its part, Mijares case exhibits a clearly dependent tendency, with its correlation coefficients outside or very close to the independence region of the correlogram (area amongst Anderson limits). 


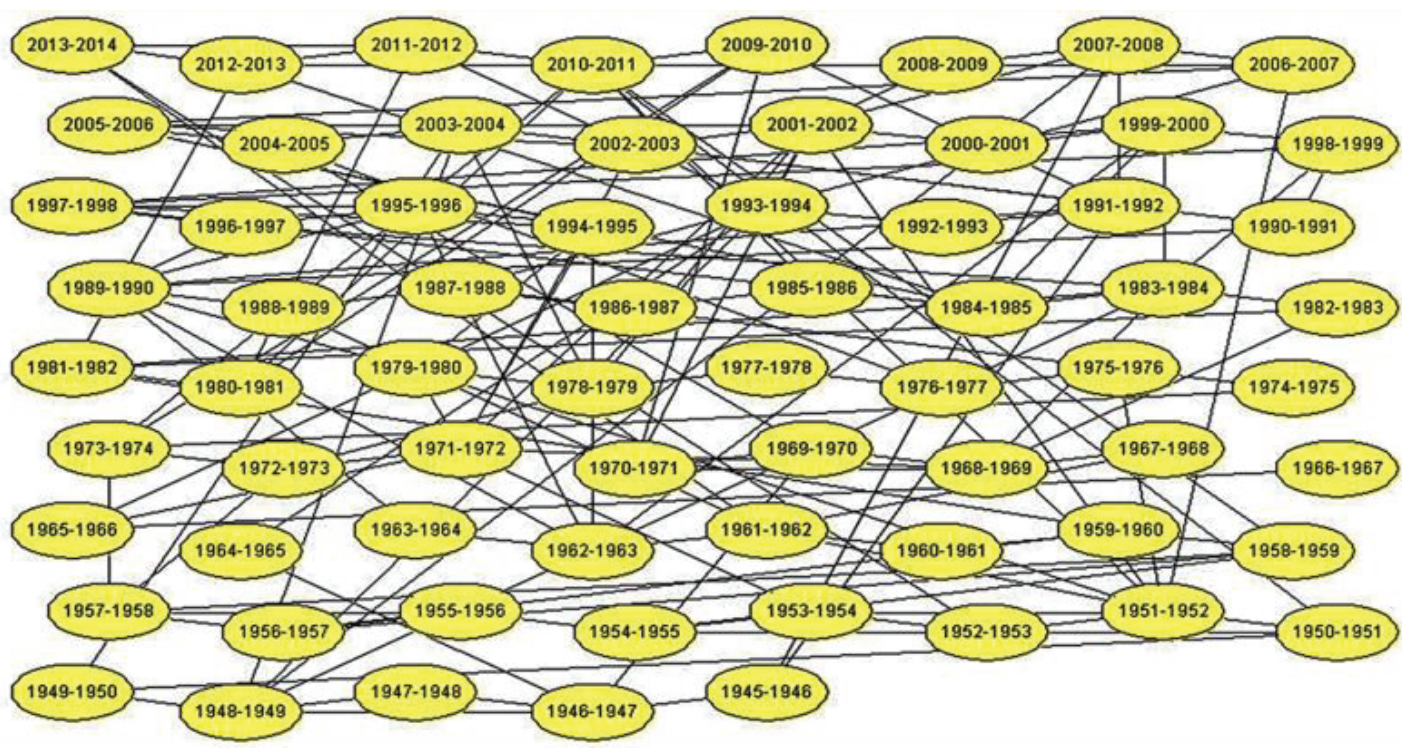

Figure 4: Mijares case study. Logical-temporal structure through Graph of Marginal Dependencies. Note: Displayed Independence level 0.05 (5\%; up to 95\% of dependence relationships are shown).

Regarding the analysis of DMGs, firstly, it should be noted that determination coefficients $\left(R^{2}\right)$ of W-MAX and W-MIN mathematical functions (polynomials in all cases) presented a very high goodness of fit (close to 1.00), with values amongst 0.97 and 0.99. Furthermore, the convergence of all series and W-MAX and W-MIN to 0 on $X$ axis (time-lags) provides the temporal horizon of the dependence influence. This is done by means of the propagation of dependence strength over time (Figure 5).

Secondly, DMG Porma presents a total lack of symmetry, with a W-MAX clearly dominant and a practically non-existent W-MIN, where it is also evident the influence the propagation of dependence strength, up to a maximum of 13 years versus 15 years of correlogram. Moreover, according to the DMG gradient, two regions can be clearly observed. The first amongst time- lags 0 and 5, where there is a rapid mitigation (high gradient), and the second one amongst time-lags 5 and 13, in which the gradient is lower, and characterized by a gradual dissipation of dependence up to a relative percentage of change of 0 .

In contrast, DMG Adaja is completely opposite. Its symmetry is practically total, with an identical W-MAX and W-MIN mitigation pattern that defines a temporal horizon of 7 years. Also, two regions are observed; the one with the highest gradient, located in the interval [0-1], and the one with the lowest gradient [1-7].

Regarding Cabriel, DMG has a significant asymmetry in the interval $[0,1]$, with a predominant W-MAX, which is corresponding to the behavior shown by the correlogram. The temporal horizon is extended up to time-lag 6 as maximum versus 10 years that correlogram offers. 
Finally, DMG Mijares case reproduces the general behavior highlights in the correlogram (basically dependent). Here, DMG is clearly asymmetric, with a W-MIN practically null. Furthermore, it is remarkable that the graph has captured the strong nature dependence of the $r k_{1}$, as it can be observed in the maximum gradient associated to interval $[0,1]$. In addition, in the same manner as in the other cases, it can be observed two regions of dependence referred to above, maximum interval [0-4] and minimum one [4-7].

Therefore, asymmetry of DMGs evidences a dependent behavior. On the contrary, the symmetry amongst both W-MAX and W-MIN highlights an independent behavior, which is the larger the more symmetrical these wrap-arounds are.

\section{Conclusions}

This research presents an innovative qualitative approach for assessing timedependency from a geometrical perspective, in a dynamic and continuous manner, against the classical, static and punctual analysis that the correlogram technique offers. This is done through a novel DMG whose analysis leads to a dependent temporal behavior in the case of an asymmetric graphic, and where an independent behavior is highlight by means of symmetry graph.

On the other side, DMG general behavior provides the temporal horizon of dependence influence, which is defined by convergence of the series to 0 on $X$ axis (timelags). Furthermore, according to greater or lesser influence of dependence strength over the time, temporal horizon analysis has allowed highlighting two particular regions into the general behavior. These could not only define a short and medium-term qualitative indicator of behavior (general), but also a very short-term indicator by means of the greater influence region (particular). Furthermore, the indeterminacy points of a correlogram ( $r k_{i}$ very close to Anderson limits) are eliminated by means of a dynamic and continuous DMG analysis. This complete and detailed information is especially useful in the current context of growing water resources variability.

However, it should be pointed that this novel methodological approach is sensitive to aspects related to the information with which the causal model is defined, such as length of annual time series (always larger than 30 years) or the necessity of normalizing the time series to generate the synthetic series by means ARMA model and then populate the $\mathrm{CR}$ process. All these aspects are currently being studied through specific research lines. 

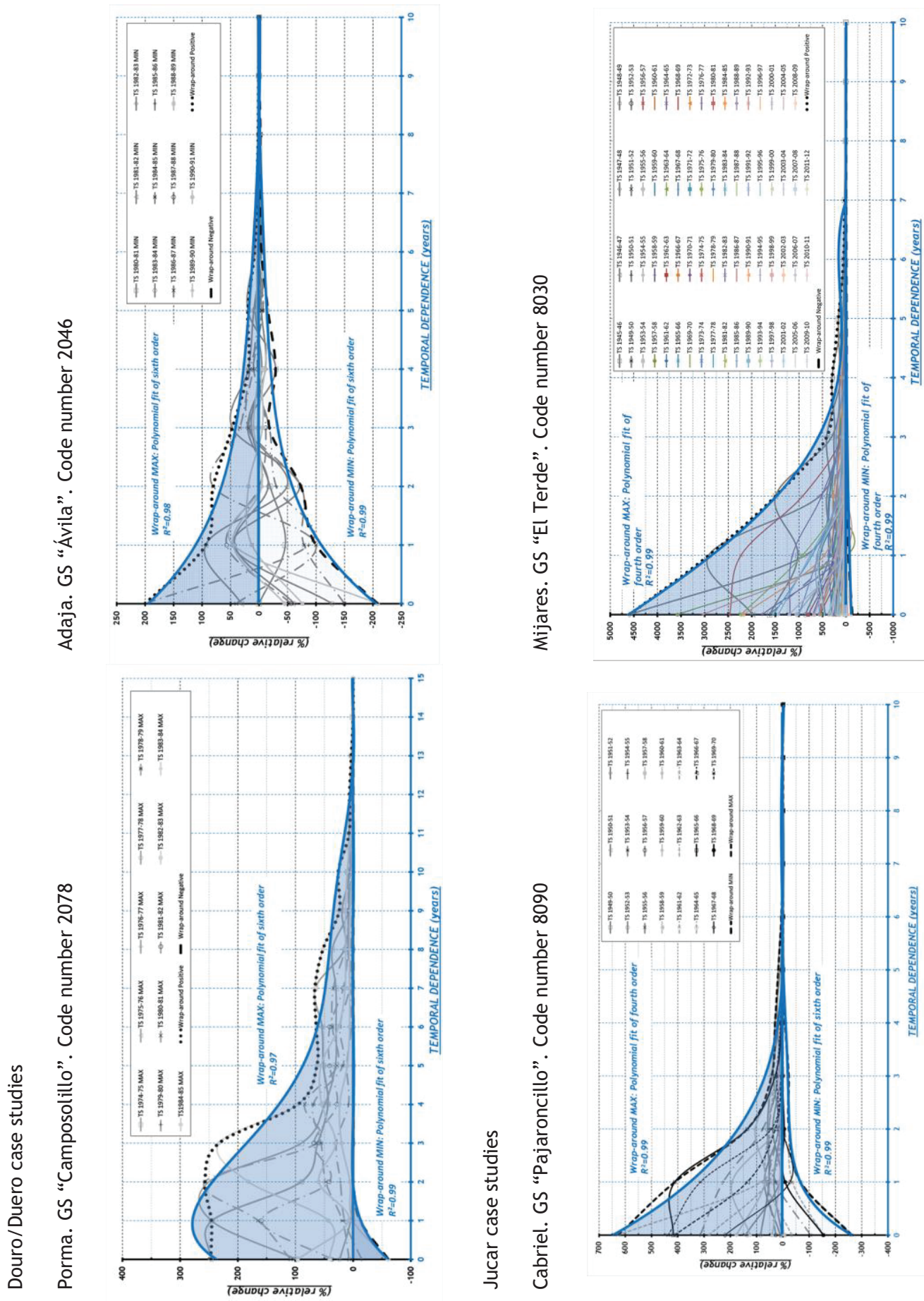

Figure 5: Dependence Mitigation Graphs.

To conclude, DMG is a graphic and visual method for analyzing and assessing runoff temporal dependence behavior of time series, which reinforces the suitability of Causality (Causal Reasoning) in modelling the temporal behavior of the water resources from a dynamic and stochastic perspective. 


\section{References}

[1] K. E. Trenberth, "Changes in precipitation with climate change," Climate Research, vol. 47, (1-2), pp. 123-138, 2011.

[2] J. L. Molina and S. Zazo, "Causal Reasoning for the Analysis of Rivers Runoff Temporal Behavior," Water Resour. Manage., vol. 31, (14), pp. 4669-4681, July 2017.

[3] J. L. Molina and S. Zazo, "Assessment of Temporally Conditioned Runoff Fractions in Unregulated Rivers," J. Hydrol. Eng., vol. 23, (5), pp. 04018015, 2018.

[4] S. Zazo et al, "Flood hazard assessment supported by reduced cost aerial precision photogrammetry," Remote Sensing, vol. 10, (10), pp. 1566, 2018.

[5] M. I. Jyrkama and J. F. Sykes, "The impact of climate change on spatially varying groundwater recharge in the grand river watershed (Ontario)," Journal of Hydrology, vol. 338, (3-4), pp. 237-250, May 2007.

[6] R. Voss, W. May and E. Roeckner, "Enhanced resolution modelling study on anthropogenic climate change: Changes in extremes of the hydrological cycle," Int. J. Climatol., vol. 22, (7), pp. 755-777, June 2002.

[7] J. L. Molina et al, "Innovative Analysis of Runoff Temporal Behavior through Bayesian Networks," Water, vol. 8, (11), pp. 484, November 2016.

[8] E. Romano et al, "Generating synthetic time series of springs discharge in relation to standardized precipitation indices. Case study in Central Italy," Journal of Hydrology, vol. 507, pp. 86-99, December 2013.

[9] J. L. Molina, S. Zazo and A. M. Martín-Casado, "Causal Reasoning: Towards Dynamic Predictive Models for Runoff Temporal Behavior of High Dependence Rivers," Water, vol. 11, (5), pp. 877, 2019.

[10] X. Kong et al, "Risk analysis for water resources management under dual uncertainties through factorial analysis and fuzzy random value-at-risk," Stochastic Environmental Research and Risk Assessment, pp. 2265-2280, 2017.

[11] J. Pearl, "Causality: models, reasoning, and inference. 2nd edn Cambridge University Press," New York, 2009.

[12] S. Zazo, "Analysis of the Hydrodynamic Fluvial Behaviour through Causal Reasoning and Artificial Vision." Doctoral Thesis, University of Salamanca, Salamanca, SPAIN, 2017.

[13] MITECO. Ministerio Para la Transición Ecológica. Gobierno de España. [Online]. Available: https://www.miteco.gob.es/es/agua/temas/seguridad-de-presas-yembalses/desarrollo/ [Accessed: Oct. 30, 2018]. 
[14] M. de Castro, J. Martín-Vide and S. Alonso, "El clima de España: pasado, presente y escenarios de clima para el siglo XXI," Evaluación Preliminar De Los Impactos En España Por Efecto Del Cambio Climático, pp. 1-64, 2005.

[15] N. Cortesi, "Variabilidad De La Precipitación En La Península Ibérica." Doctoral Thesis, University of Zaragoza, Zaragoza, SPAIN, 2013.

[16] E. Vallarino et al, Tratado Básico De Presas. Tomo I: Generalidades - Presas De Hormigón Y De Materiales Sueltos. Colección SENIOR No 11. (5 $5^{\mathrm{a}}$ edición ed.) Madrid: Colegio de Ingenieros de Caminos, Canales y Puertos, 2001.

[17] MITECO. Ministerio Para la Transición Ecológica. Gobierno de España. [Online]. Available: https://sig.mapama.gob.es/redes-seguimiento/ [Accessed: Oct. 30, 2018].

[18] CHJ. Confederación Hidrográfica del Júcar. Ministerio Para la Transición Ecológica. Gobierno de España. [Online]. Available: https://www.chj.es/es-es/medioambiente/ cuencahidrografica/ [Accessed: Jan. 8, 2019].

[19] H. Macian-Sorribes, M. Pulido-Velazquez and A. Tilmant, "Definition of efficient scarcity- based water pricing policies through stochastic programming," Hydrology and Earth System Sciences, vol. 19, (9), pp. 3925-3935, 2015.

[20] Vidiani. Maps of all countries in one place. [Online]. Available: http://www.vidiani. com/large-detailed-satellite-map-of-spain/ [Accessed: Jun. 16, 2019].

[21] CEDEX, "Evaluación del impacto del Cambio Climático en los recursos hídricos y sequías de España," vol. Tomo Único, July 2017.

[22] B. C. Trewin, "Función de las normales climatológicas en un clima cambiante," Programa Mundial De Datos Y Vigilancia Del Clima. Documento WCDMP,(61), 2007.

[23] HUGIN, "Hugin Expert A/S, version 7.3". Aalborg, DENMARK: Hugin Expert, http: //www.hugin.com, 2010. 